\title{
Obligatory versus voluntary energy audits: are there differences in quality?
}

\author{
Michael C. KRUTWIG \\ The Bucharest University of Economics Studies (ASE), Bucharest, Romania \\ michael@krutwig.com \\ Adrian TANȚĂU \\ The Bucharest University of Economics Studies (ASE), Bucharest, Romania \\ adrian.tantau@fabiz.ase.ro
}

\begin{abstract}
Directive 2012/27/UE of the European Parliament has created a new motivation for energy audits: the avoidance of penalties. According to this directive, large companies in all EU member states must carry out energy audits at least every four years. Does this obligation affect the quality of energy audits? We hypothesize that voluntary audits, in comparison to mandatory audits, have a higher quality level in terms of a higher investment in energy efficiency measures. While mandatory audits must always take the entire company into account, voluntary energy audits allow companies to focus on the most promising business or process areas. The energy balance limits can also be drawn more focused. The auditor can also be selected according to specific professional qualifications. As a methodology, we first define quality criteria for energy audits based on the energy efficiency measures determined. Important factors are the adoption rate, the calculated energy savings and the consideration of non-energy benefits in the calculation. The validation of the collected quality criteria is carried out by a comparison with the results of already existing research work. In an empirical study, we then compare data from audits of both types that have already been carried out with regard to the quality characteristics found. Via a database with 1,692 energy audits conducted in Germany in the years 2014-2016, we can draw up detailed comparisons of the energy balances and, in particular, of the measures calculated. This enables clear conclusions to be drawn about the differences in quality between the different program types.
\end{abstract}

Keywords: energy audits, audit quality, mandatory audits, voluntary audits.

\section{Introduction}

As the EU Directive 2012/27/UE (Parliament, 2012) of the European Parliament (EED) has been incorporated into national legislation in Germany (Bundestag, 2010), there have been numerous programs to promote energy efficiency in companies. While SMEs have been motivated to carry out audits and consultations with subsidy programs such as "Energy Consulting for Medium-Sized Enterprises" (EBM) (BAFA, 2017a), the nonSMEs have been obliged to carry out an energy audit throughout Europe since 2015, unless they have already introduced a management system in accordance with ISO 50001 or EMAS. The energy audits shall be repeated every four years. The supervising authority in Germany is the BAFA, which (BAFA, 2017b) defines the regulations for carrying out audits. If a company does not comply with this obligation, fines of up to EUR 50,000 may be imposed in Germany. A good overview of the various national implementations of the EED and, in particular, of the audit obligations in Europe can be found (Hirzel, 2016).

Now, it is suspicious that forced energy audits are not always carried out with the same passion as sponsored voluntary audits. If the company's motivation is to avoid punishment, it will give priority to the minimization of audit costs rather than to the maximization of the company's energy efficiency. The purpose of this investigation is to 
contribute to the clarification of this situation. The hypothesis of this work is, thus: there is a qualitative difference between voluntary and mandatory energy audits. In this context, the question of how quality is defined in energy audits and how it can be measured is interesting.

In addition to a review of the existing literature, which evaluates individual audits as well as audit programs, we can make use of the anonymized data from "energieparbericht. de" (ESB), a software tool for the online generation of audit reports, as the only data provider. ESB is offered as commercial software as a service (SaaS). It has been in existence since July 2015 and serves companies and energy consultants for the easy and efficient preparation of reports on energy audits. Users can enter all data such as energy procurement, energy use, consumers, buildings, processes, and measures. The system then supports the calculation of energy balances and efficiency calculations and outputs an audit report that follows the DIN EN 16247-1 (16247$1: 2012,2012)$ standard. The database contains very detailed data such as energy purchase, usage, consumer lists, calculated efficiency measures and many more over 2,000 energy audits. The tool is used both for the compilation of mandatory energy audits and for voluntary, subsidized programs such as EBM, the promotion of crosscutting technologies ((BAFA, 2016) and the so-called "SpitzenausgleichEffizienzsystemverordnung" (SpaEfV) ((Bundestag, 2013). Thus, there is a database that allows a comparison between mandatory and voluntary audits.

In order to investigate the above hypothesis, the importance of quality in connection with energy audits must first be clarified. What is the definition of quality and what factors influence it? For this purpose, findings from the literature are collected and the main arguments from these sources for this study are extracted and summarized.

Since, in addition to the many non-energy benefits (NEBs) that have been investigated in many cases, the potential energy saved is a strong quality criterion for energy audits, we consider existing evaluations of audit programs, divided into voluntary and mandatory programs. These data serve as reference values for our own figures. To the best of our knowledge, there is so far only one study (Andersson, Arfwidsson, Bergstrand, \& Thollander, 2017) that specifically examines the comparability between audit programs and makes recommendations for improved cross-audit evaluations. This work contributes to the continuation of Andersson's study. In addition to the direct energy savings, the inclusion of non-energy benefits (NEBs) is also an important factor in the high-quality performance of energy audits, which is why a compact examination of the studies on the NEBs is an integral part of this study.

\section{Quality in energy audits}

The standard DIN EN 16247-1 is a good starting point in the search for quality requirements for energy audits (16247-1:2012, 2012). This standard specifies general requirements for audits. It distinguishes between quality requirements for the auditor and requirements for the audit process. With regard to the auditor, competence, confidentiality, objectivity, and transparency are defined. The audit process itself must be appropriate, complete, representative, traceable, relevant, and verifiable. Another important contribution to quality assessment based on the adoption rate is in (Fleiter, Schleich, \& Ravivanpong, 2012). Here, the authors discuss concrete proposals for increasing the quality of energy audits, which are:

- Development of standards (such as DIN EN 16247)

- Mandatory report templates 
- Competence criteria for the auditors (e. g. certificates)

- The use of software tools (such as energieparbericht. de)

- Fixed methods for costing tasks (for example, lifecycle methods)

- Follow-up cooperation with the auditor for implementation and evaluation measures after the audit.

When introducing mandatory templates, a structured characterization of the efficiency measures (Fleiter, Hirzel, \& Worrell, 2012) and the non-energy benefits (Krutwig \& Starosta, 2017) can also help to objectively assess and prioritize the EEM. Especially, the report template and the software tool can also contribute to a better cross-audit evaluation.

In our study, we compare energy consumption with efficiency potential. The role of energy efficiency indicators (EEI) and, in particular, the relationship between energy intensity and energy efficiency will be examined (Proskuryakova \& Kovalev, 2015). This relationship provides only indirect and delayed evidence of (technologically defined) energy efficiency. The pure energy intensity is rather a measure of consumption and does not provide any indication of potential savings.

Ball, Tyler, \& Wells (2015) investigate the personal relationship between the auditor and the company as a factor influencing quality in the context of financial audits. Accordingly, a regular rotation of the auditing company is recommended in order to avoid excessive bias and thus increase the audit quality.

Numerous studies have shown that the inclusion of non-energy benefits (NEBs) in the calculation of efficiency measures has a partly significant effect on profitability and thus on the adoption rate. (Pye \& McKane, 2000) show, through three case studies, that the NEBs also provide additional arguments for energy efficiency measures. In the report of (Lazar \& Colburn, 2013) the NEBs are generally considered in terms of energy efficiency, i.e. not only in terms of EEM, and are divided into three target groups: utility, participant/consumer, and society. The program evaluation of (Dennis Pearson, 2002) underlines the importance of NEBs for the marketing and targeting of programs. The average NEB share of savings in this study is 40\%. Also, (Worrell, Laitner, Ruth, \& Finman, 2003) recommend that productivity benefits should be included in profitability. In the study presented here, $63 \%$ of the calculations show that the NEB even exceeds the energy benefits and the time of amortization is reduced from 4.2 to 1.9 years if NEBs are included in the calculation of the EEM. Similar results are also described (Lung, McKane, Leach, \& Marsh, 2005) from 81 renewable energy projects of a US program. Good information on the measurability of NEBs is provided by (L. Skumatz, 2014) and (L. A. Skumatz \& Gardner, 2005). In the latter, various scenarios are provided in which the quantification of NEBs can be useful: reducing barriers to the adoption of programs, drafting funding programs, marketing programs. (Rasmussen, 2014), who derives specific suggestions from the current state of research, provides an overview of NEB with a literature search. (Freed \& Felder, 2017) provide a rather critical analysis of the previous research on NEBs, pointing to numerous shortcomings and inconsistencies in existing studies.

Overall, the following influencing factors on the quality of energy audits can be determined from all these sources:

- the time available

- the available budget

- the thoroughness of carrying out the audit

- the professional competence of the auditors

- the company's willingness and availability to participate in the audit 
- availability and completeness of the documents

How can the quality of an energy audit be measured? The following characteristics can be appropriately measured:

- completeness of the analysis within defined balance limits

- maximizing the savings potential by discovering all energy efficiency opportunities (EEOs)

- completeness and correctness of the calculation of the measures, also

PICBE $\mid 525$ taking into account any existing NEBs

- the duration of the execution (the shorter the better)

- the cost of the energy audit (the lower the better)

- completeness and conformity of the audit report

- other, often subjective factors such as cooperation with the auditor, the perceived competence of the auditor, continued support in implementing the measures and monitoring the results

The effectiveness of an audit can finally be assessed by adopting the EEOs. The higher the quality, the higher the adoption rate (Fleiter, Schleich, et al., 2012).

It can be seen that the savings potential or the number of measures must not be a quality feature for energy audits, as even in an "energetically perfect" company, a highquality audit must be possible. However, we assume in our study that in our random samples for the characteristic "maximization of the savings potential" there is no difference between mandatory and voluntary audits, so that the savings potential in percentage of the total energy use has meaningfulness as to how well these potentials have been found.

\section{Existing evaluations of audit programs Studies on voluntary audit programs}

There is a rich amount of studies on audit programs that are voluntary for the participants. For better comparability with our own data, some results from other studies are presented in the following.

An evaluation of the SME audit program "Sonderfonds Energieeffizienz in KMU" is provided by (Fleiter, Gruber, Eichhammer, \& Worrell, 2012) and (Frahm et al., 2010). This energy audit scheme exists from 2008 in Germany. The results provide an average of 5.3 EEM per company with an adoption rate of 1.7-2.9. The savings per company are 117.5 - 197.5 MWh. In (Backlund \& Thollander, 2015), the Swedish energy audit program SEAP for SMEs (2010-2013) is studied. They examine the costs and results of the program, the adoption rate is 53\% and the energy savings per company is $860-1270$ $\mathrm{MWh}$ /year. An evaluation of the EEM funding program "Highland" for the manufacturing industry in Sweden is available (Thollander, Danestig, \& Rohdin, 2007). This section deals with the following three questions: 1 . which EEMs have been implemented/planned? The work provides an evaluation of completed, planned, and unplanned actions, as well as a ranked list of barriers and driving forces for EEM. Potential energy savings amount to $8.8 \%$ of the total energy input, with an average of 5.9 measures per company being found.

In the work of (Fresner, Morea, Krenn, Uson, \& Tomasi, 2017), a total of 280 audits of the European PINE project in seven countries are investigated. The focus here is on the manufacturing industry. The audit procedure consists of six steps, in which a quick overview is first created and then a decision is made individually on the balance sheet limits. The total savings here amount to 8,420.12 MWh per company (all years). By interviewing 140 participants, an average potential overall saving of $679.03 \mathrm{MWh}$ of 
primary energy per company $(8,174$ toe for all) would be achieved if all measures were implemented. Analysis confirms, among other things, the known obstacles. According to this study, an average of around 5\% (range 1.5\% - 7.5\%) of energy costs can be saved across all SMEs. There is also a quantification of quality: the customer satisfaction rate averaged $88 \%$.

\section{Studies on obligatory efficiency programs}

PICBE | 526

The following two sources both refer to the EED. The study by (Rosenow \& Bayer, 2017) examines energy efficiency commitments (EEOs) in 15 European countries on the costeffectiveness of the various programs. The study proves a general cost-effectiveness of EEOs, useful comparative figures are not provided by the study.

The final report on the energy audit requirement (Michael Mai, 2017) in Germany is based on an extensive survey and thus offers an interesting comparison with our evaluation of the report data. The analysis covers both mandatory audits and the management systems introduced as an alternative to ISO 50001 or EMAS. In all comparisons between this study and our figures, it should be noted that each sample represents an audit, i.e. an energy balance and, therefore, companies with several sites are represented by several audits. In the mandatory audits, we have an average of two audits/locations per company. According to (Michael Mai, 2017) the average value lies at 631.59 MWh per company (292 samples). In an extrapolation, the study shows a savings potential of $3.5 \%$ to $7.5 \%$ per year in terms of final energy consumption.

Finally, it should be noted that an indirect obligation is also defined. These are mandatory efficiency measures as a prerequisite for granting voluntarily requested benefits. One example is the "Spitzenausgleich" (Bundestag, 2013) in Germany, which grants companies a tax relief if they introduce an energy management system according to ISO 50001 or EMAS.

\section{Data collection methodology}

Usually, evaluations of audit programs are carried out by a survey using questionnaires. However, our approach is completely different and largely unique. The possibility of using the ESB database enabled us to access fine-grained audit data from a relatively large number of energy audits. We have the disadvantage of not being able to make an evaluation of the adoption of measures but we have the advantage of a very extensive and detailed set of figures, as it would never be possible in surveys. As described in (Michael Mai, 2017), the number of responses to surveys decreases significantly when specific figures are requested.

The work was extensive elsewhere: an analysis tool had to be programmed for the empirical evaluation of the ESB database. The data of the energy audits in the ESB system are distributed over a number of more than 60 linked database tables, so that the generation of sample data cleansing was a considerable challenge for this work. Webbased analysis software had to be programmed to calculate the annual energy balances and the potential savings of the audits according to selectable filter criteria from the numerous data and makes them available as finished sample data. Filters for cleaning the data had to be defined and implemented. These sample files with a total of 1,692 audits (Figure 1) were then exported as a file and analyzed empirically with the statistics program PSPP. 


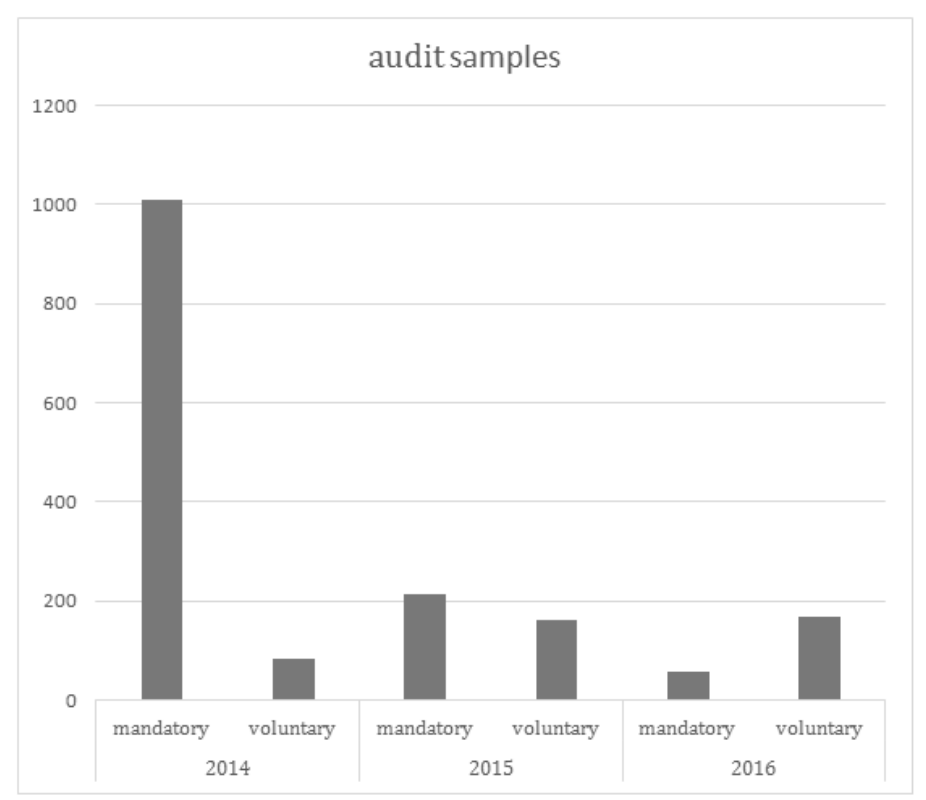

PICBE $\mid 527$

Figure 1: Number of viewed audits

Source: Authors' own research.

To get a better understanding of the data used, a short description of the SaaS is given. ESB is an online service that enables energy consultants and companies to generate audit reports on different types of energy audits. Companies are divided by site. A company can thus receive several audit reports, one report per site resp. per energy balance. The usage fee is based on the number of locations, the price is valid for one year. There is no automatic renewal of the license, the system remains usable even after the license expires and the data is retained.

All audits comply with the standard DIN EN 16247-1; however, the output differs slightly in the type of later use, for example as a report on a mandatory energy audit or in the context of an application for funding. Users enter data for the following three main areas: inventory data, annual values, and analysis.

Inventory data includes all buildings, consumers, facilities, processes and facilities for energy production. The data set of the consumers is relatively detailed: e. $\mathrm{g}$. service life, energy carrier, performance, load, maintenance costs and many other data are collected. All energy sources are converted into $\mathrm{kWh}$ in consumption, further data such as CO2 factors and costs can also be recorded. The figures collect the annual data on energy purchases, energy production, energy consumption for each consumer and other factors such as utilization factors and key figures. Depending on the type of audit, up to three past calendar years can be recorded. Together with the inventory data, this results in the energy balances. The analysis describes, classifies, assigns, calculates, evaluates, plans, and prioritizes the efficiency measures found. For each measure, there is, therefore, a calculation with savings potential, costs, service life, interest rate, cost, and $\mathrm{CO} 2$ savings. ESB also offers numerous other functions that are not relevant for our consideration. The task of our analysis tool is to calculate the energy balances and savings for each audit and to offer this information in the form of a file as samples for export.

The challenge of analyzing this data was that the system did not have reliable information about the completeness and correctness of the data collected, nor did it have any information about the actual use of the reports. In particular, before April 2016, the license model offered contingents for audits so that customers sometimes purchased more licenses than required and could use the remaining for testing purposes with a small amount of test data. After April 2016, every single audit report was subject 
to licensing fees and customers could purchase exactly as they needed it. There are also a small number of licenses that have been issued via a voucher and, therefore, may only be used for test reports. In order to determine and filter out these "bad" audits, we have installed several filters to clean the data. For example, test companies known to us were explicitly excluded. Only audits were also carried out, which included measures and included data for both energy purchases and consumers. A plausibility check filter for the relationship between energy consumption and energy consumption carried out further adjustments. By applying this data cleansing, 1,692 audits out of a total of 2,243 audit reports were taken over as samples.

After applying these cleanup filters, you can also set content filters for the analysis of subsets of content. For example, you can create samples that only include audits for a specific year and/or audit type. Filters are also available for industries, for operating areas (buildings, heating, lighting...) and for energy sources. We've only used the filters for audit-type and the year to generate six sample files over three years. For the criterion "mandatory", we have only selected audit reports of the type "EDL-G according to DIN EN 6247-1" for simple audits and so-called multisite audits ((BAFA, $2017 \mathrm{~b}$ ). For the criterion "voluntary", we have taken audit reports of five types (energy consulting for small and medium-sized enterprises, cross-sectional technologies, SpaEfV in several forms), which stand for voluntary funding programs. The year of sampling is not the year of the audit but the year of the (complete) energy balance.

\section{Analysis of the Audit Report Generation Tool \\ Data sources}

The collected, cleaned, and filtered sample data from the audits were then transferred to the statistics program PSPP and analyzed separately by year and type. The two most interesting values are energy use and savings, as we calculate the potential savings from the percentage ratio of these two values. As the samples had to be filtered for data cleansing, it is important to observe the description and the percentiles, which are given in Table 1 and Table 2. Here, for example, it can be observed that the minimum savings can be zero or even negative. This is not a mistake, but rather the character of a few unusual efficiency measures.

Table 1. Descriptives of all valid audit samples (all years)

\begin{tabular}{|c|c|c|c|c|c|}
\hline & Audit type & & & Statistic & Std. Error \\
\hline \multirow{14}{*}{$\begin{array}{l}\text { Energy use } \\
\text { [kWh] }\end{array}$} & \multirow[t]{9}{*}{ Obligatory } & \multicolumn{2}{|l|}{ Mean } & 2570607.58 & 599626.16 \\
\hline & & \multirow[t]{2}{*}{ 95\% Conf. Interval for Mean } & Lower Bound & 1394249.55 & \\
\hline & & & Upper Bound & 3746965.60 & \\
\hline & & \multicolumn{2}{|l|}{ 5\% Trimmed Mean } & 1159396.86 & \\
\hline & & \multicolumn{2}{|l|}{ Median } & 499540.40 & \\
\hline & & \multicolumn{2}{|l|}{ Variance } & 460585514581582.50 & \\
\hline & & \multicolumn{2}{|l|}{ Std. Deviation } & 21461256.13 & \\
\hline & & \multicolumn{2}{|l|}{ Minimum } & 3436.00 & \\
\hline & & \multicolumn{2}{|l|}{ Maximum } & 748650591.00 & \\
\hline & \multirow[t]{5}{*}{ Voluntary } & \multicolumn{2}{|l|}{ Mean } & 874131.90 & 84610.91 \\
\hline & & \multirow[t]{2}{*}{ 95\% Conf. Interval for Mean } & Lower Bound & 707806.57 & \\
\hline & & & Upper Bound & 1040457.22 & \\
\hline & & \multicolumn{2}{|l|}{ 5\% Trimmed Mean } & 615686.90 & \\
\hline & & \multicolumn{2}{|l|}{ Median } & 268463.00 & \\
\hline
\end{tabular}




\begin{tabular}{|c|c|c|c|c|c|}
\hline & & \multicolumn{2}{|l|}{ Variance } & 2942351512146.54 & \\
\hline & & \multicolumn{2}{|l|}{ Std. Deviation } & 1715328.40 & \\
\hline & & \multicolumn{2}{|l|}{ Minimum } & 7044.00 & \\
\hline & & \multicolumn{2}{|l|}{ Maximum } & 22239221.00 & \\
\hline \multirow{18}{*}{$\begin{array}{l}\text { Savings } \\
\text { [kWh] }\end{array}$} & \multirow[t]{9}{*}{ Obligatory } & \multicolumn{2}{|l|}{ Mean } & 165194.11 & 21956.02 \\
\hline & & \multirow[t]{2}{*}{ 95\% Conf. Interval for Mean } & Lower Bound & 122120.38 & \\
\hline & & & Upper Bound & 208267.85 & \\
\hline & & \multicolumn{2}{|l|}{$5 \%$ Trimmed Mean } & 75041.02 & \\
\hline & & \multicolumn{2}{|l|}{ Median } & 28000.00 & \\
\hline & & \multicolumn{2}{|l|}{ Variance } & 617527579045.99 & \\
\hline & & \multicolumn{2}{|l|}{ Std. Deviation } & 785829.23 & \\
\hline & & \multicolumn{2}{|l|}{ Minimum } & -584281.00 & \\
\hline & & \multicolumn{2}{|l|}{ Maximum } & 17368508.00 & \\
\hline & \multirow[t]{9}{*}{ Voluntary } & \multicolumn{2}{|l|}{ Mean } & 168292.54 & 16714.68 \\
\hline & & \multirow[t]{2}{*}{ 95\% Conf. Interval for Mean } & Lower Bound & 135435.37 & \\
\hline & & & Upper Bound & 201149.71 & \\
\hline & & \multicolumn{2}{|l|}{ 5\% Trimmed Mean } & 106374.07 & \\
\hline & & \multicolumn{2}{|l|}{ Median } & 50968.00 & \\
\hline & & \multicolumn{2}{|l|}{ Variance } & 114825460170.05 & \\
\hline & & \multicolumn{2}{|l|}{ Std. Deviation } & 338859.06 & \\
\hline & & \multicolumn{2}{|l|}{ Minimum } & 0.00 & \\
\hline & & \multicolumn{2}{|l|}{ Maximum } & 2118704.00 & \\
\hline
\end{tabular}

PICBE $\mid 529$

Table 2. Percentiles of the kWh-Values (all years)

\begin{tabular}{|l|l|c|c|c|c|c|c|c|}
\hline \multirow{2}{*}{ Audit_type } & \multicolumn{7}{|c|}{ Percentiles (Average) } \\
\cline { 3 - 9 } & \multicolumn{2}{|c|}{5} & 10 & 25 & 50 & 75 & 90 & 95 \\
\hline $\begin{array}{l}\text { Energy_use } \\
{[\mathrm{kWh}]}\end{array}$ & Mand. & 23063.63 & 48168.20 & 133847.89 & 499540.40 & 1583318.00 & 5020731.84 & 8542902.15 \\
\cline { 2 - 9 } & Volunt. & 34386.00 & 53462.40 & 119000.00 & 268463.00 & 831572.00 & 2417256.30 & 4314063.60 \\
\hline $\begin{array}{l}\text { Savings } \\
{[\mathrm{kWh}]}\end{array}$ & Mand. & 441.00 & 1182.60 & 5980.00 & 28000.00 & 100501.00 & 348720.00 & 555514.43 \\
\cline { 2 - 9 } & Volunt. & 1365.60 & 3720.00 & 14800.00 & 50968.00 & 154306.80 & 462605.20 & 774768.80 \\
\hline
\end{tabular}

Source: Authors' own research.

\section{Results}

The large number (1009) of mandatory audits for 2014 is based on the legal regulations: the deadline for submission was December 5, 2015, but in the following years, delayed laggards were still carried out. As the next deadline is December 2019, we anticipate a large increase in mandatory audits for the year 2018 and the continuous slight increase in voluntary audits can be explained by an approximately equivalent increase in the utilization rate of the ESB service.

The overall results are described in Table 3. Based on the values for energy purchasing and energy consumption, it is easy to see that the obligatory audits are carried out by non-SMEs while the voluntary audits are mostly the result of SME programs. The percentage savings potential for voluntary audits is approximately three times higher than for mandatory audits. Surprisingly, however, voluntary audits also reveal almost always higher absolute savings and a higher number of measures found. 
Table 3: Overview of the results

\begin{tabular}{|c|c|c|c|c|c|c|}
\hline & \multicolumn{2}{|c|}{2014} & \multicolumn{2}{|c|}{2015} & \multicolumn{2}{|c|}{2016} \\
\hline & Mandatory & Voluntary & Mandatory & Voluntary & Mandatory & Voluntary \\
\hline \# Audits & 1009 & 82 & 215 & 162 & 57 & 167 \\
\hline \# Companies & 585 & 72 & 130 & 143 & 29 & 158 \\
\hline Procurement [MWh] & $3.695 .274,20$ & $101.973,66$ & $468.922,81$ & $111.590,91$ & $114.327,50$ & $145.842,06$ \\
\hline Avg. per audit [MWh] & $3.662,31$ & $1.243,58$ & $2.181,03$ & 688,83 & $2.005,74$ & 873,30 \\
\hline Energy use [MWh] & $2.706 .583,78$ & $101.634,37$ & $472.055,30$ & $111.595,93$ & $114.309,21$ & $146.037,89$ \\
\hline Avg.per audit [MWh] & $2.682,44$ & $1.239,44$ & $2.195,60$ & 688,86 & $2.005,42$ & 874,47 \\
\hline \# Consumers & 69451 & 4378 & 16233 & 6623 & 5693 & 6971 \\
\hline Avg. per audit & 68,83 & 53,39 & 75,50 & 40,88 & 99,88 & 41,74 \\
\hline \#Measures & 2937 & 350 & 790 & 654 & 237 & 625 \\
\hline Avg.per audit & 2,91 & 4,27 & 3,67 & 4,04 & 4,16 & 3,74 \\
\hline Savings p.a. [MWh] & $163.707,63$ & $18.151,77$ & $40.037,65$ & $24.703,88$ & $7.868,37$ & $26.312,58$ \\
\hline Avg. per audit [MWh] & 162,24 & 221,36 & 186,22 & 152,49 & 138,04 & 157,56 \\
\hline Use/savings (\%) & $6,0485 \%$ & $17,8599 \%$ & $8,4816 \%$ & $22,1369 \%$ & $6,8834 \%$ & $18,0176 \%$ \\
\hline
\end{tabular}

PICBE | 530

Source: Authors' own research.

\section{Conclusion}

To date, the scientific evaluation of audit programs has always been carried out through surveys. This unconventional approach by evaluating a report database opens up new possibilities and perspectives on audits, in particular through the availability of very detailed figures. On the other hand, correction filters had to be created in order to minimize the data's deficiencies in terms of correctness and completeness. The relatively large number of samples allows scientific observation.

Are voluntary energy audits carried out with a higher quality? The result of this study provides a very reliable indication of a 'yes' - but no proof yet. On the one hand, the correlation between mandatory/voluntary and non-SME/SME would have to be investigated; on the other hand, the form of data cleansing does not provide absolute certainty about the data quality. Nor can it be assumed with any certainty that the amount of energy saved must inevitably be a sign of quality. Due to the high number of samples and the detailed figures available for the audits, the significance of the result is nevertheless of great relevance. A two to three times higher energy saving in voluntary audits clearly supports the preliminary hypothesis.

As the ESB tool will continue to be in used in the future and potentially valuable data will yield thousands of energy audits, we are proposing a few improvements that will lead to improved data quality for evaluations. The system shall be extended by elements with "survey character". For example, users should be able to explicitly set the status (draft, test report, submitted, purpose and date of submission) of an audit report, which would make numerous filters for data cleansing unnecessary. A small management system should be added for the efficiency measures entered, so the status (draft, proposed, planned, executed, rejected, etc.) of each measure is also explicitly set by the user. In this way, a certain amount of certainty can be gained about the usability of the data for the evaluation. In particular, information on the adoption of measures is an important quality feature that could not yet be taken into account in the current form.

With regard to the evaluations of other studies under consideration, I can observe a high range of energy savings and the average adoption rate for the EEM. In this respect, we have to conclude that almost none of the studies investigated give a representative relevance for energy audits in general. Here we support the recommendations of (Andersson et al., 2017) in their study of the comparability of 
energy audit program evaluations and recommend the inclusion of other elements such as NEB consideration and differentiation about voluntariness.

\section{Acknowledgments}

Special thanks to Kejo Starosta and Oliver Schulz for their support. Michael Reetz, Ingo Herrmann, and Sven Lenhart deserve special appreciation for their assistance in PICBE|531 developing the analysis software.

\section{References}

DIN EN 16247-1 (2015). 16247-1 DIN EN16247-1: Energieaudits-Teil 1: Allgemeine Anforderungen. Oktober 2012. Deutsches Institut für Normung e. V.

Andersson, E., Arfwidsson, O., Bergstrand, V., \& Thollander, P. (2017). A study of the comparability of energy audit program evaluations. Journal of Cleaner Production, 142, 2133-2139. Elsevier BV.

Backlund, S., \& Thollander, P. (2015). Impact after three years of the Swedish energy audit program. Energy, 82, 54-60. Elsevier BV.

BAFA. (2016). Einzelmaßnahmen. Merkblatt für für Anträge nach 3.1.1 der Richtlinie für Investitionszuschüsse zum Einsatz hocheffizienter Querschnitstechnologien. Bundesamt für Wirtschaft und Ausfuhrkontrolle (BAFA).

BAFA. (2017a). Energieberatung im Mittelstand. Merkblatt für Anträge nach der Richtlinie über die Förderung von energieberatungen im Mittelstand. Bundesamt für Wirtschaft und Ausfuhrkontrolle (BAFA).

BAFA. (2017b). Merkblatt für Energieaudits nach den gesetzlichen Bestimmungen der $\S \S 8 \mathrm{ff}$. EDL-G. Bundesamt für Wirtschaft und Ausfuhrkontrolle (BAFA).

Ball, F., Tyler, J., \& Wells, P. (2015). Is audit quality impacted by auditor relationships? Journal of Contemporary Accounting \& Economics, 11(2), 166-181. Elsevier BV.

Bundestag, D. (2010). Gesetz über Energiedienstleistungen und andere Energieeffizienzmaßnahmen (EDL-G). Bundesministeriums der Justiz und für Verbraucherschutz. Deutscher Bundestag.

Bundestag, D. (2013). Verordnung über Systeme zur Verbesserung der Energieeffizienz im Zusammenhang mit der Entlastung von der Energie- und der Stromsteuer in Sonderfällen (Spitzenausgleich-Effizienzsystemverordnung - SpaEfV). Bundesministeriums der Justiz und für Verbraucherschutz. Deutscher Bundestag.

Dennis Pearson, L. S. (2002). Non-Energy Benefits Including Productivity, Liability, Tenant Satisfaction, and Others - What Participant Surveys Tell Us about Designing and Marketing Commercial Programs. Proceedings of the 2002 Summer Study on Energy Efficiency in Buildings.

Fleiter, T., Gruber, E., Eichhammer, W., \& Worrell, E. (2012). The German energy audit program for firms - a cost-effective way to improve energy efficiency? Energy Efficiency, 5(4), 447-469. Springer Nature.

Fleiter, T., Hirzel, S., \& Worrell, E. (2012). The characteristics of energy-efficiency measures - a neglected dimension. Energy Policy, 51, 502-513. Elsevier BV.

Fleiter, T., Schleich, J., \& Ravivanpong, P. (2012). Adoption of energy-efficiency measures in SMEs-An empirical analysis based on energy audit data from Germany. Energy Policy, 51, 863-875. Elsevier BV.

Frahm, B.-J., Gruber, E., Mai, M., Roser, A., Fleiter, T., \& Schlomann, B. (2010, November). Evaluation des Förderprogramms „Energieeffizienzberatung“ als eine Komponente des Sonderfonds' Energieeffizienz in kleinen und mittleren Unternehmen (KMU), Schlussbericht. Institut für Ressourceneffizienz und 
Energiestrategien GmbH (IREES) and Fraunhofer-Institut für System- und Innovationsforschung ISI.

Freed, M., \& Felder, F. A. (2017). Non-energy benefits: Workhorse or unicorn of energy efficiency programs? The Electricity Journal, 30(1), 43-46. Elsevier BV.

Fresner, J., Morea, F., Krenn, C., Uson, J. A., \& Tomasi, F. (2017). Energy efficiency in small and medium enterprises: Lessons learned from 280 energy audits across Europe. Journal of Cleaner Production, 142, 1650-1660. Elsevier BV.

Hirzel, T. Nabitz Wohlfarth Rohde Behling Clarke Perera. (2016). A Study on Energy Efficiency in Enterprises: Energy Audits and Energy Management Systems. Official Journal of the European Union. European Union.

Krutwig, M., \& Starosta, K. (2017). Characterization, Classification and Assessment of Non-Energy Benefits of Energy Efficiency Measures. Proceedings of 30th IBIMA Conference, Madrid 2017. IBIMA.

Lazar, J., \& Colburn, K. (2013). Recognizing the Full Value of Energy Efficiency. The Regulatory Assistance Project (RAP).

Lung, R. B., McKane, A., Leach, R., \& Marsh, D. (2005). Ancillary Savings and Production Benefits in the Evaluation of Industrial Energy Efficiency Measures.

Michael Mai, A. S. Edelgard Gruber Natalja Ashley-Belbin. (2017, July). Analyse der Entwicklung des Marktes und Zielerreichungskontrolle für gesetzlich verpflichtende Energieaudits. Schlussbericht an das BAFA.

Parliament, E. (2012). Directive 2012/27/UE of The European Parliament and of the Council of 25 October 2012 on energy efficiency, amending Directives 2009/125/EC and 2010/30/EU and repealing Directives 2004/8/EC and 2006/32/EC. Official Journal of the European Union. European Union.

Proskuryakova, L., \& Kovalev, A. (2015). Measuring energy efficiency: Is energy intensity a good evidence base? Applied Energy, 138, 450-459. Elsevier BV.

Pye, M., \& McKane, A. (2000). Making a stronger case for industrial energy efficiency by quantifying non-energy benefits. Resources, Conservation and Recycling, 28(3-4), 171-183. Elsevier BV.

Rasmussen, J. (2014). Energy-efficiency investments and the concepts of non-energy benefits and investment behaviour. eceee Industrial Summer Study Proceedings : Retool for a competitive and sustainable industry (Vol. 2, pp. 733-744). Linköping University, Business Administration.

Rosenow, J., \& Bayer, E. (2017). Costs and benefits of Energy Efficiency Obligations: A review of European programmes. Energy Policy, 107, 53-62. Elsevier BV.

Skumatz, L. (2014). Non Energy Benefits/Non Energy Impacts (NEBs/NEIs) and Their Role and Values in Cost-Effectiveness Tests: State of Maryland. Skumatz Economic Research Associates, Inc. (SERA).

Skumatz, L. A., \& Gardner, J. (2005). Methods and results for measuring non-energy benefits in the commercial and industrial sectors introduction : NEBs as omitted effects. ACEEE summer study on energy efficiency in industry: cutting the high cost of energy. New York: West Point; 2005. p. 163-76.

Thollander, P., Danestig, M., \& Rohdin, P. (2007). Energy policies for increased industrial energy efficiency: Evaluation of a local energy programme for manufacturing SMEs. Energy Policy, 35(11), 5774-5783. Elsevier BV.

Worrell, E., Laitner, J. A., Ruth, M., \& Finman, H. (2003). Productivity benefits of industrial energy efficiency measures. Energy, 28(11), 1081-1098. Elsevier BV. 